
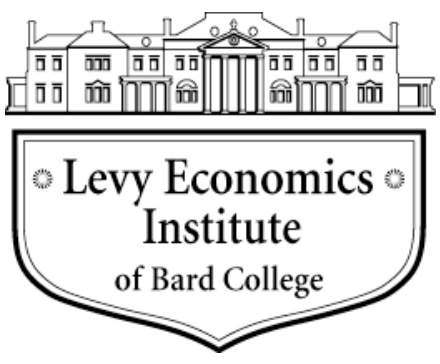

Working Paper No. 850

\title{
The Macroeconomics of a Financial Dutch Disease
}

by

\author{
Alberto Botta* \\ Department of Law and Economics, \\ Mediterranean University of Reggio Calabria, Italy (on leave); \\ Department of International Business and Economics, University of Greenwich
}

October 2015

\footnotetext{
* Department of Law and Economics, Mediterranean University of Reggio Calabria, and Department of Economics and Management, University of Pavia. Correspondence: Department of Economics and Management, via San Felice 5, 27100, Pavia, Italy; abotta@eco.unipv.it.
}

The Levy Economics Institute Working Paper Collection presents research in progress by Levy Institute scholars and conference participants. The purpose of the series is to disseminate ideas to and elicit comments from academics and professionals.

Levy Economics Institute of Bard College, founded in 1986, is a nonprofit, nonpartisan, independently funded research organization devoted to public service. Through scholarship and economic research it generates viable, effective public policy responses to important economic problems that profoundly affect the quality of life in the United States and abroad.

\author{
Levy Economics Institute \\ P.O. Box 5000 \\ Annandale-on-Hudson, NY 12504-5000 \\ http://www.levyinstitute.org
}

Copyright (C) Levy Economics Institute 2015 All rights reserved 


\begin{abstract}
We describe the medium-run macroeconomic effects and long-run development consequences of a financial Dutch disease that may take place in a small developing country with abundant natural resources. The first move is in financial markets. An initial surge in foreign direct investment targeting natural resources sets in motion a perverse cycle between exchange rate appreciation and mounting short- and medium-term capital flows. Such a spiral easily leads to exchange rate volatility, capital reversals, and sharp macroeconomic instability. In the long run, macroeconomic instability and overdependence on natural resource exports dampen the development of nontraditional tradable goods sectors and curtail labor productivity dynamics. We advise the introduction of constraints to short- and medium-term capital flows to tame exchange rate/capital flows boom-and-bust cycles. We support the implementation of a developmentalist monetary policy targeting competitive nominal and real exchange rates in order to encourage product and export diversification.
\end{abstract}

Keywords: Financial Dutch Disease; Exchange Rate Volatility; Macroeconomic Instability; Developmentalist Monetary Policy

JEL Classifications: F32, O14, O24 


\section{INTRODUCTION}

In the last two decades, widespread consensus has been reached that the liberalization of financial markets and free capital movements are major causes of macroeconomic volatility and vulnerability (Krugman 1999; Stiglitz 2002; Gallagher, Griffith-Jones, and Ocampo 2012). Economists mainly focus on portfolio investment when they investigate these issues, highlighting its short-term horizon and quick reversibility. On the contrary, foreign direct investment (FDI) is usually positively considered: in the case of developing countries, for instance, it is believed to contribute to domestic capital formation and enhance labor productivity through the "import” of more advanced technologies.

However, this view on FDIs as a source of long-run progress is not unanimous. FDI's effects depend on the way they integrate into the productive system of the recipient economy, hence on their real contribution to domestic capital accumulation and technological knowledge (Lall 2000; Singh 2003). In this sense, the sectorial pattern of incoming FDI is likely to be a decisive factor (Dutt 1997): FDIs in the natural resource sector are rather different from those targeting domestic manufacturing. The former usually regards separate enclaves within the productive system of the host economy and is very likely to increase its dependence on the export of natural resources, thus possibly exacerbating Dutch disease effects. On the other hand, FDIs in the manufacturing sector exhibit a higher potential in terms of long-term growth with the creation and diffusion of technological progress.

The literature on the Dutch disease usually describes it as a real-side phenomenon whose causes lie on the real side of the economy. In other words, natural resource booms or huge international aid flows tend to increase domestic expenditure and alter domestic relative prices in favor of non-tradable goods. Such appreciation of the real exchange rate negatively impacts on the development of non-traditional tradable sectors, reducing their profitability and competitiveness. A deindustrialization process is likely to eventually take place, possibly curtailing long-run growth potential (Sachs and Warner 1995, 2001; Ros 2001). In a way, traditional Dutch disease models emerge as real-side models that overlook the monetary implications of natural resource booms, i.e., the effects they may trigger on the external balance and financial solidity of the economies under observation (see Corden and Neary 1982). We think this is a relevant shortcoming. First, the lack of a precise national account framework in most Dutch disease models does not enable them to consider the possibility that natural resource booms might influence the economic dynamics by 
feeding the excessive accumulation of foreign liabilities and giving rise to boom-and-bust cycles. ${ }^{1}$ This hypothesis was originally put forward by Manzano and Rigobon (2001) in their econometric work on the economic performance of natural-resource-abundant countries in 1970s and 1980s. Second, when natural resource booms lead to mounting FDI inflows, the financial sphere of an economy is affected through a change in the external net investment position. According to Singh (2003, 209), these effects cannot be neglected, since "FDI creates foreign exchange liabilities not only now but also into the future [so that] unfettered FDI may create a time profile of foreign exchange outflows and inflows which may be time inconsistent."

The aim of this paper is to contribute to the literature on the Dutch disease and the effects of natural-resource-based FDI on the economic dynamics of developing countries. Unlike previous Dutch disease models, we primarily consider how natural-resource-based FDI may affect the macroeconomic stability of recipient economies and we elaborate and introduce the concept of financial Dutch disease. FDIs targeting developing countries’ natural resources directly affect their productive structure (and consequently their growth potential), but also affect their external balance equilibrium. In a flexible exchange rate regime, for instance, long-term FDIs may induce the exchange rate to appreciate. Exchange rate appreciation, which is first nominal and then real, may attract additional portfolio investment by reducing perceived country risks or increasing capital gains expectations. Portfolio capital inflows in turn feed back on exchange rate dynamics and may lead to an even stronger appreciation.

Two undesirable scenarios may possibly arise from this process. First, exchange rate appreciation impinges on the profitability of domestic manufacturing, reduces its external competitiveness, and likely leads it to shrink with respect to the natural resource sector. This corresponds to what is usually claimed by traditional Dutch disease models, even though in this paper it will be determined by financial and monetary—say nominal—mechanisms rather than realside ones. Second, and perhaps more relevantly, the aforementioned economic spiral may abruptly reverse if economic agents evaluate the accumulation of foreign debt and the exchange rate appreciation as being unsustainable processes. The ensuing quick capital reversals, the collapse of the exchange rate, and macroeconomic instability represent may jeopardize the long-run growth potential—and the development of the manufacturing sector in particular-since productive investment in the real business sector is usually highly sensitive to boom-and-bust cycles. To sum up, these phenomena all originate in the financial markets as a consequence of FDI inflows. An

\footnotetext{
${ }^{1}$ Standard Dutch disease models formalize external imbalances into perfect-foresight infinite-lifetime frameworks. Accordingly, external borrowing and rising foreign debt today are fully repaid by increasing domestic savings and rising current account surpluses tomorrow (see Bruno and Sachs 1982; Mansoorian 1991; Ojeda, Parra-Polonia, and Vargas 2014). In these models, boom-and-bust cycles and possible episodes of foreign debt overhang are avoided by assumption.
} 
apparently traditional Dutch disease actually develops through rather unusual mechanisms that are mainly connected to the overall external soundness of an economy. This is why we label it a financial Dutch disease. ${ }^{2}$

The paper is organized as follows. Section 2 illustrates the macroeconomic characteristics of the financial Dutch disease. Section 3 shows how such macroeconomic dynamics can affect the sectorial composition of an economy and thus the overall labor productivity dynamics. Section 4 concludes by outlining some policy implications in order to deal with FDI flows, macroeconomic volatility, and the long-run growth potential of a developing country.

\section{THE MACROECONOMICS OF A FINANCIAL DUTCH DISEASE}

This article is a spin-off a previous publication on macroeconomic dynamics in current-day Colombia following the booming FDI inflows in the domestic oil sector (Botta, Godin, and Missaglia 2014). This work goes beyond the specific Colombian case and tries to provide a more general theoretical framework. More precisely, we intend to analyze the case of small open developing economies exhibiting three characteristics.

First, the economy has a significant endowment of natural resources and consequently attracts a huge amount of FDIs. Second, the economy is open to free trade and free capital movements. The primary objective of macroeconomic policy is price stability and monetary policy is implemented via inflation targeting (Masson, Savastano, and Sharma 1997; Minshkin 2000; Gemayel, Jahan, and Peter 2011). ${ }^{3}$ Third, consistent with an inflation-targeting monetary policy, the nominal exchange rate is free to float (Masson, Savastano, and Sharma 1997; Mishkin 2000; Epstein and Yeldan 2009). The domestic central bank can intervene to manage exchange rate dynamics (or takes it into account in defining its benchmark interest rate) in order to achieve the inflation target (Edwards 2006). Central bank intervention is promptly implemented in the event of exchange rate depreciation that may put domestic price stability at risk, increasing “imported”

\footnotetext{
${ }^{2}$ In a way, this paper provides a formal representation of what Ocampo (2013) defines a "Balance of Payments dominance" regime, i.e., a macroeconomic framework in which macroeconomic dynamics are determined by external shocks, boom-and-bust cycles in external financing in particular. The kind of shock we have in mind is an initial surge in FDIs targeting developing countries' natural resources.

${ }^{3}$ Masson, Savastano, and Sharma (1997) and Mishkin (2000) list a series of institutional developments that are considered fundamental prerequisites in order to make inflation targeting effective and credible in developing countries. Emphasis is put on the introduction of an independent and accountable central bank, the removal of fiscal dominance, and the development of a deep and free financial sector (intended as a side product of fiscal dominance's removal).
} 
inflation. Much less concern exists in case of appreciation trends that increase domestic purchasing power and reduce inflationist pressures. ${ }^{4}$

Finally, both long-term FDI and short- and medium-term portfolio investment are allowed. For the sake of simplicity, we assume FDIs to concentrate only in the domestic natural resource sector. Portfolio investment mainly takes the form of short- and medium-term foreign debt (denominated in foreign currency), namely bills or financial loans. ${ }^{5}$ Equities are not considered, but such simplification does not modify the logic of our model and the economic mechanisms we are investigating.

The model consists of two non-linear differential equations. In chapter 10 of Reconstructing Macroeconomics, Lance Taylor (2004a) develops a model of financial cycles in developing countries. He assumes a fixed exchange rate regime and describes the dynamics of foreign reserves as resulting from surpluses or deficits in the sum of the current and financial account of the balance of payments (BoPs). In this paper we present the "flexible exchange rate version" of that external balance equation. The exchange rate dynamics (rather than the variation in foreign reserves) are now the endogenous outcome of the interactions among the various components of the BoP:

$\dot{e}=e\left\{\left[\operatorname{imp}_{M}(e)-\frac{\exp _{M}(e)}{e}\right]-\exp _{N R}+i_{H} D+\pi_{N R}+\dot{R}-K A_{P I}\left(i_{H}-i_{F}-\sigma(e, D)\right)-K A_{F D I}(N)\right\}$

Following Taylor (2004b), equation (1) does not show the traditional Mundell-Fleming dichotomy between a flexible exchange rate and endogenous foreign reserves as adjusting variables for short-run external imbalances. In fact, equation (1) does not determine any instantaneous equilibrium level of the exchange rate $e$, but simply takes into account all the possible factors included in the BoPs, i.e., trade flows, net income transfers, and financial flows that may give rise to an excess of demand or supply for the domestic currency on the currency market.

Equation (1), for instance, shows that exchange rate dynamics are strongly influenced by, among other factors, interest rate differentials and country-factor risk premia, which modify portfolio income decisions — and thus net portfolio capital flows—-hence determining changes and

\footnotetext{
${ }^{4}$ See Galindo and Ros (2006) on the asymmetric response of Mexican monetary authorities to exchange rate appreciation and depreciation. Mohanty and Klau (2005) provide evidence about monetary policy's asymmetric responses to inflation shocks (tougher against positive shocks than against negative ones) for a larger sample of emerging economies. Interestingly, Pontines and Siregar (2012) find a stronger response of domestic central banks against appreciation rather than depreciation in the case of Indonesia, South Korea, Philippines, and Malaysia from 2000 to 2006. After the East Asian crisis at the end of the 1990s, even in the (formal) context of an inflation-targeting monetary policy, these countries have paid attention to maintaining a competitive nominal and real exchange rate in order to avoid current account deficits.

${ }^{5}$ See Mishkin (1999), Taylor (1998), Neftci (1998), and Frenkel and Rapetti (2009) on the short-term structure of foreign liabilities of domestic agents, financial intermediaries in particular, in the emerging economies affected by financial and currency crises in 1990s.
} 
perhaps temporary trends in the exchange rate dynamics $\dot{e}$. In broader terms, equation (1) formalizes massive capital inflows and then reversals that, following Frenkel and Rapetti (2009), have repeatedly led to strong exchange rate appreciation and abrupt collapses in many developing countries and emerging economies. Within this framework, foreign reserves turn out to be the exogenous policy instrument in the hands of domestic monetary authorities, through which they may try to tame or even reverse pressures on exchange rate appreciation ${ }^{6}$ or control exchange rate devaluations and avoid collapses in presence of mounting capital outflows (insofar as reserves are available).

Equation (1) distinguishes between imports and exports of manufactured goods as expressed in foreign currency, $\operatorname{imp}_{M}$ and ( $\exp _{M} / e$ ), respectively; foreign currency-denominated exports of domestic natural resources $\exp _{N R}$, such as oil; interest payments on foreign debt $i_{H} D$; foreign firms' profit repatriation out of natural resource revenues $\pi_{N R}$; domestic central bank's variations of foreign reserves $\dot{R}$; net portfolio capital inflows $K A_{P I}$; and net FDI $K A_{F D I}$. We assume that foreign firms' profit repatriation $\pi_{N R}$ is a constant share $\alpha$ of natural resource exports $\exp _{N R}$.

As far as manufactured goods are concerned, their imports are denominated in foreign currency and negatively respond to nominal exchange rate depreciation (i.e., higher $e$ values), whereas their exports are denominated in domestic currency and positively respond to such the depreciation of $e$. Actually, manufactured goods imports and exports, as well as the viability of nontraditional tradable good sectors, are also affected by relative price dynamics among trading partners, and therefore by the real exchange rate dynamics rather then by the nominal one only. However, relative price dynamics may prove of secondary importance in this model. First, the financial Dutch disease we describe mainly affects the nominal exchange rate set on the currency market rather than the real one through changes in relative prices. ${ }^{7}$ Second, inflation-targeting monetary policy can at least partially restrain inflation lifts, due to abundant capital inflows. Relative inflation rate dynamics among trading partners may be of minor concern with respect to what has been observed in the recent past in presence of fixed exchange rate regimes. Third, developing countries' inflation, if relevant, may easily reach higher levels than those observed in foreign economies — developed ones in particular. ${ }^{8}$ The inclusion in our model of relative price changes would simply reinforce the kind of dynamics we already illustrated. For the sake of simplicity, we choose not to focus on relative price dynamics.

\footnotetext{
${ }^{6}$ This is the case of many East Asian countries and China when, in the case of large surpluses in their external accounts, they keep their exchange rate devaluated by piling up a huge amount of foreign reserves.

${ }^{7}$ Goda and Torres (2013) provide empirical evidence supporting such interpretation of the Dutch disease episode currently underway in Colombia.

${ }^{8}$ See Frenkel and Rapetti (2009) on the ensuing real exchange rate appreciation experienced by many developing countries after capital account liberalization.
} 
We assume that portfolio investment usually takes the form of foreign-currencydenominated short-term bills or loans. Accordingly, foreign lenders do not bear any direct exchange rate risk. The amount of net portfolio capital inflows is simply determined by the interest rate differential $\left(i_{H}-i_{F}\right)$ — with $i_{H}$ and $i_{F}$, respectively being the domestic and foreign interest rate —and by the country-factor risk $\sigma$. Yet, portfolio net capital flows are related to exchange rate dynamics through the lender-borrower default risk. The more appreciated the domestic exchange rate (i.e., low e values) the more domestic borrowers' financial position will be sound and the more easily domestic borrowers will meet their payment commitments in foreign currency. It follows that the country-factor risk will decrease and portfolio investment increases. In the same vein, a depreciation of the exchange rate will make the foreign debt burden less sustainable and domestic borrowers' default risk higher. In this case, the ensuing increase in the country-risk factor $\sigma$ will curtail (and perhaps reverse) net portfolio capital flows. Therefore, the domestic exchange rate and short-term portfolio capital flows are connected by an indirect relationship. ${ }^{10}$

Net FDI $K A_{F D I}$ is assumed not to depend on the exchange rate, since it targets domestic natural resources that are exported on international markets and sold in foreign currency. It is positively influenced by the available stock of domestic natural resources $N$.

Equation (2) makes explicit our assumption of net portfolio capital flows mainly consisting of short- and medium-term bills or financial loans, thus representing foreign debt variations:

$\dot{D}=K A_{P I}\left(i_{H}-i_{F}-\sigma(e, D)\right)$

With $\left(\partial K A_{P I} / \partial \sigma\right)<0 ;(\partial \sigma / \partial e)>0 ;(\partial \sigma / \partial D)>0$

Equation (2) also states a reasonable negative relationship between the current level of foreign indebtedness $D$ and its own dynamics. The higher the foreign debt stock is, the less likely foreign lenders are to increase their exposition towards domestic economic agents by providing new credit. Therefore, there exists a negative relationship between $D$ and $\dot{D}$. It implies self-stabilizing dynamics take place as to the accumulation of foreign debt.

\footnotetext{
${ }^{9}$ We assume the domestic interest rate $i_{H}$ to be an exogenous policy variable managed by the domestic central bank in order to achieve its inflation target.

${ }^{10}$ Such an assumption likely holds true, even in the case of equity holding as an alternative investment option with respect to bills or loans. Exchange rate appreciation may in fact increase expected capital gains on domestic equities and stimulate portfolio investment to come in and flood the economy. In the end, foreign investment on domestic bills, equities, and the provision of loans may all co-move. They may strongly increase in times of financial euphoria and suddenly dry up when signs of deep external imbalances emerge.
} 
Whilst most of the partial derivatives' signs are clear in equation (2), something more must be said about stable/unstable exchange rate dynamics. Deriving equation (1) with respect to the current exchange rate in the neighborhood of the steady state and after some mathematical passages, we get:

$\left.\frac{\partial \dot{e}}{\partial e}\right|_{\dot{e}=0}=\frac{\exp _{M}}{e}\left\{\eta_{\text {imp }_{M}}^{e} \chi-\eta_{\exp _{M}}^{e}+1\right\}-e \frac{\partial K A^{P I}}{\partial \sigma} \frac{\partial \sigma}{\partial e}$

With $\chi=\frac{i m p_{M}}{\left(\exp _{M} / e\right)}$ as the manufacturing import-export ratio; $e \frac{\left(\partial i m p_{M}(e) / \partial e\right)}{i m p_{M}}=\eta_{i m p_{M}}^{e}$ and $e \frac{\left(\partial \exp _{M}(e) / \partial e\right)}{\exp _{M}}=\eta_{\exp _{M}}^{e}$ as manufactured good import and export elasticities to the exchange rate.

The above equation (3) defines the negative or positive effect that an exchange rate shift may have on its own dynamics. The first part of equation (3) is the well-known Marshall-LearnerRobinson condition in the case of an initial (manufacturing) trade imbalance. The last decades have been characterized by widespread financial deregulation, which has made financial transactions overwhelmingly relevant in explaining exchange rate dynamics. Correspondingly, the second part of equation (3) takes into account how an exchange rate shift may affect net capital flows, portfolio investment in particular. The sign of equation (3) can be either negative (a depreciated current exchange rate tames further depreciation) or positive (unstable feedbacks in the exchange rate dynamics). In this regard, the more liberalized the capital account is, the more intensively capital movements will respond to exchange rate shifts. This fact might outstrip possible stabilizing effects passing through trade flows and give rise to exchange rate instability. In the rest of the paper we assume the unstable scenario to apply.

The effect of a higher foreign debt stock $D$ on the exchange rate dynamics is clearly positive. A higher debt stock induces the nominal exchange rate to depreciate faster. First, an increase in $D$ will lead foreign lenders to be more skeptical about new credit lines granted to the home economy, so that $(\partial \sigma / \partial D)>0$. Portfolio investment, as well as the demand for domestic currency, might decrease. Second, higher debt stocks imply tougher debt burdens and heavier interest payments. The demand for foreign currency will increase and the domestic exchange rate will depreciate. The positive link between $D$ and $\dot{e}$ is formally stated in the derivative below:

$$
\left.\frac{\partial \dot{e}}{\partial D}\right|_{\dot{e}=0}=e i_{H}-e \frac{\partial W A_{P I}}{\partial \sigma} \frac{\partial \sigma}{\partial D}>0
$$




\subsection{Joint Macroeconomic Dynamics of the Exchange Rate and of the Foreign Debt}

According to the economic relationships encapsulated in equations (1) and (2), dynamics in the exchange rate and foreign debt stock can be described according to the Jacobian matrix $J$ :

$$
J=\stackrel{\dot{e}}{\dot{D}}\left[\begin{array}{ll}
+ & D \\
- & -
\end{array}\right]
$$

The signs of partial derivatives in matrix $J$ reveal that both geometric loci for constant values of $e$ and $D$ slope downward. Should the $(\dot{D}=0)$ locus be steeper than the locus for $(\dot{e}=0)$, the system will be unstable. On the contrary, a substantially flat locus for $(\dot{D}=0)$, in particular flatter than the isocline for ( $\dot{e}=0)$, will open space to stability. A focus will emerge. Cyclical fluctuations around the equilibrium point will be stable and convergent to equilibrium should the Jacobian matrix's trace tr. $(J)$ be negative. If the matrix's trace is positive, diverging cycles will take place.

Figure 1. Joint medium-run dynamics in the exchange rate and in the foreign debt stock

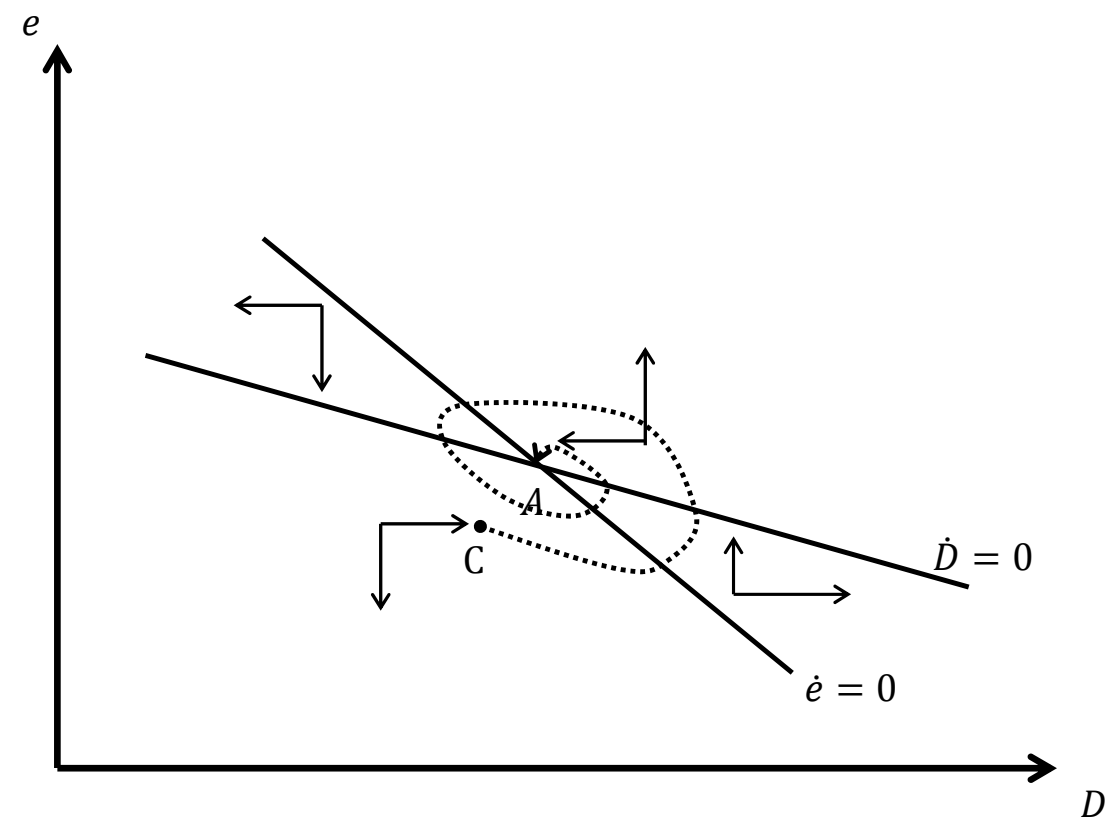

Possible converging fluctuations characterizing such an economic system are portrayed in figure 1. If an economy initially lies in point $\mathrm{C}$, its external account will register a surplus. Therefore, $\dot{e}$ will be negative and the nominal exchange rate will appreciate. A decreasing domestic borrower's risk (or the possibility of capital gains on the domestic equity market) will induce 
foreign portfolio investment to flow in. A foreign credit boom likely takes place and foreign debt increases. ${ }^{11}$ The exchange rate appreciates even further, jeopardizing home economy manufacturing exports, favoring imports, and leading to a wider manufactured good trade deficit. Once the trajectory of the economy crosses the isocline for $(\dot{e}=0)$, an external account deficit occurs; $\dot{e}$ turns into positive and the exchange rate starts depreciating, even though short- and medium-term portfolio investment continues to flow in at least for a brief period. Sudden stops, capital reversals, and exchange rate collapses eventually take place once the economy's trajectory passes the isocline for $(\dot{D}=0)$. Facing a depreciating exchange rate and an excessively high foreign debt stock, foreign investors will fear that domestic borrowers will not honor their payment commitments. External financial support rapidly dries up and external debt/exchange rate twin crises break out, with harsh effects on the real side of the economy. ${ }^{12}$

\subsection{A Natural Resource-FDI Boom}

Let us assume now that new natural resources are discovered. This fact likely leads to a spike in net FDI targeting domestic natural resources, so that $W A_{F D I}$ increases. From a graphical point of view, the isocline for ( $\dot{e}=0)$ shifts rightwards, as shown in figure 2. A new equilibrium point $B$ emerges. Cases of cyclical dynamics like those described in figure 1 will, in turn, affect an economic system originally located in the initial equilibrium $A$.

The exchange rate will first appreciate and attract additional short- and medium-term portfolio investment. Positive FDI, portfolio investment, and the increasing export flows of natural resources contribute to crowd out manufactured goods exports and give rise to a widening manufacturing trade deficit, with significantly appreciated nominal and real exchange rates. However, the appreciation of the domestic currency and the attraction of foreign portfolio investment do not last long. The widening manufacturing trade gap and foreign firms' profit repatriations (partially compensating for the increase in natural resource exports) will sooner or later lead to an overall external deficit and downward pressures on domestic currency (i.e., a positive value of $\dot{e}$ ). The turning point in the exchange rate dynamics can take place even before if

\footnotetext{
${ }^{11}$ In Colombia, the initial surge in FDIs has been more recently followed by positive and increasing net foreign portfolio investment. In the first half of the 2000s, portfolio investment in Colombia was close to zero or even negative. Since 2007-with the only exception of 2008 - it has exhibited positive values. From 2011 to 2013, according to data provided by the Central Bank of Colombia, it amounted to more than $\$ 5.5$ billion yearly, more than $1.5 \%$ of Colombian GDP. In the first quarter of 2014, it stood at more than $\$ 2.5$ billion.

${ }^{12}$ Mishkin $(2000,6)$ is well aware that, in presence of high capital mobility and of an inflation-targeting monetary policy, higher exchange rate volatility may seriously put at risk the financial solidity of the domestic economy. He stresses that "in many emerging market countries the balance sheets of firms, households and banks are substantially dollarized [...] Since inflation targeting necessarily requires nominal exchange rate flexibility, exchange rate fluctuations are unavoidable. However, a large and abrupt depreciation may increase the burden of dollar-denominated debt and produce a massive deterioration of the balance sheets, increasing the risks of a financial crisis."
} 
FDIs decrease in a few years due to the progressive exhaustion of domestic natural resources [in figure 2 , the locus for ( $\dot{e}=0$ ) will partially move back to the original position].

\section{Figure 2. Fluctuations induced by an initial surge in FDI}

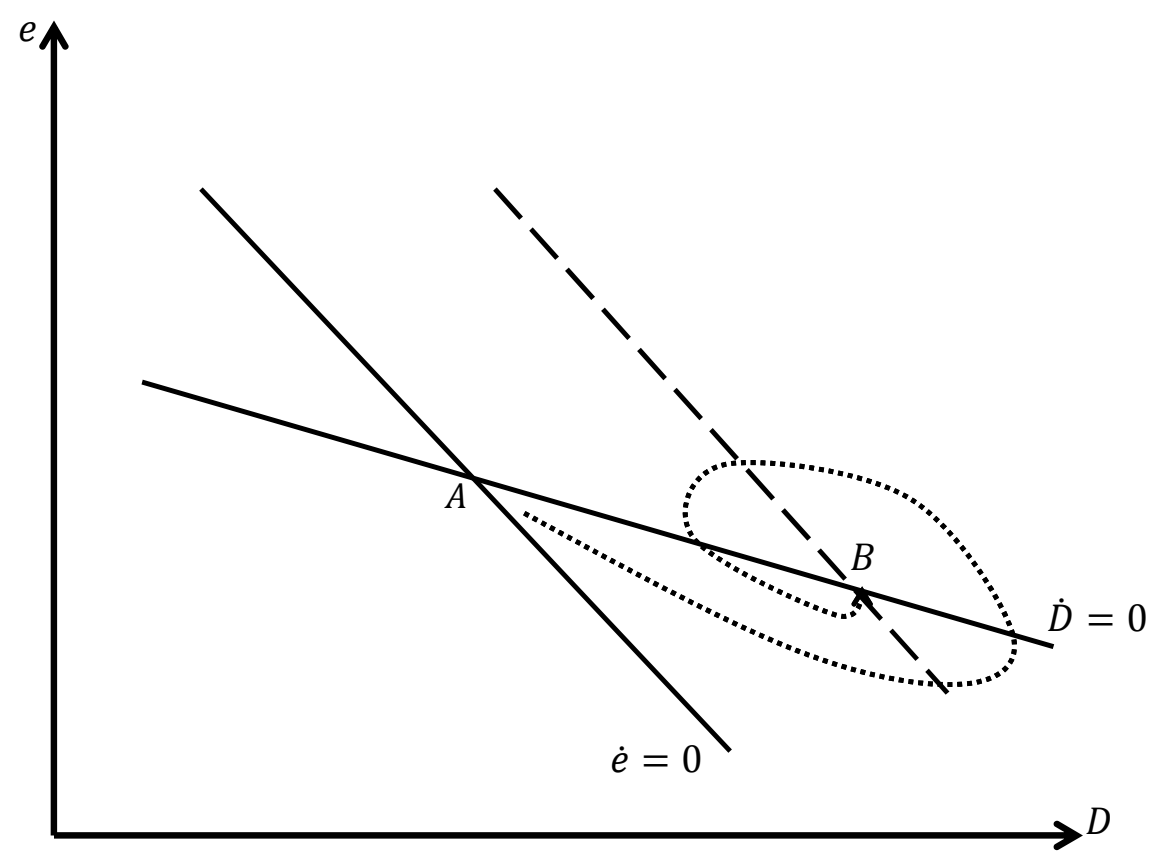

Regardless of the converging or diverging nature of such economic dynamics, it is clear that an initial surge in FDI may eventually ignite boom-and-bust cycles. Exchange rate volatility and quick capital reversals may in turn determine the disruption of economic activity, and perhaps lead to a protracted period of economic stagnation if the domestic financial sector is severely hurt by these turbulences.

Following Rodrik (2007), both exchange rate appreciation and exchange rate volatility undermine the development of non-traditional tradable sectors. Manufacturing production, exports and, above all, investment decisions are often planned in advance on a long-run time horizon. Uncertainty emerging from the above fluctuations can discourage entrepreneurs from implementing new production processes and undertaking investment projects whose profitability cannot be assessed on a sufficiently solid basis. FDI targeting developing countries' natural resources may eventually negatively affect manufacturing and the overall development process in three ways. First, they may induce a direct negative effect by shifting the domestic productive structure away from manufacturing towards a deeper dependence on natural resources. Second, higher natural resource exports may determine a secular long-run appreciation of the domestic currency, thus 
making domestic manufacturing less competitive, profitable, and viable. Third, manufacturing development may be even further hindered by the uncertainty associated with macroeconomic fluctuations generated by perverse feedbacks between FDI, exchange rate appreciation, and shortand medium-term portfolio capital movements. Policymakers should seriously pay attention to the medium-run and long-run effects of such a financial Dutch disease.

\section{LONG-RUN CONSEQUENCES OF THE FINANCIAL DUTCH DISEASE}

In the previous section, we discussed that macroeconomic volatility and vulnerability characterizing what we called financial Dutch disease. The first move is on financial markets and takes the form of huge FDI inflows targeting domestic natural resources. Exchange rate appreciation, also due to increasing natural resource exports, follows closely and interacts with short- and medium-run capital movements into a perverse spiral eventually undermining long-run manufacturing development. Let us now focus more in detail on the possible long-run consequences of such dynamics.

Our analysis rests on the well-known literature attributing specific growth-enhancing properties to manufacturing. This standpoint dates back to the 1960 s and to the theoretical contributions by Nicholas Kaldor. More recently, this perspective has been formally reinterpreted in several models on the natural resource curse (see Sachs and Warner 1995, 2001; Ros 2001). From an empirical point of view, Imbs and Warzciag (2003) and Klinger and Lederman (2004) note that development process significantly hinges on the diversification of a country’s productive structure. Manufacturing provides more opportunities than other sectors in terms of innovation and enlargement of the production space. Consequently, manufacturing development represents a “positive” structural change that feeds growth (Rodrik 2009; McMillan and Rodrik 2011) and may

prove to be the engine of economic take off (Rajan and Subramanian 2011), providing the basis for productive and export activities of non-traditional tradable goods. Even though manufacturing may play a less relevant role for economic growth in the era of the digital economy than in the "golden age” of capitalism, it may still represent a leading factor in the growth process of developing countries (Lavopa and Szirmai 2012).

In order to further clarify this point, equation (4) formalizes in the simplest way possible some of the factors affecting manufacturing development. Manufacturing development is proxied by manufacturing contribution to real GDP. 
$m=f\left(e, \rho, W A_{P I}, K_{N R}\right)$

With $(\partial m / \partial e)>0 ;\left(\partial m / \partial W A_{P I}\right)<0 ;\left(\partial m / \partial K_{N R}\right)<0$

In equation (4), we first assume that non-resource-based tradable good sectors (as a share of GDP) are positively affected by a depreciated exchange rate. This assumption relies on the considerable body of literature that defines exchange rate policy as one of the most effective industrial policies favoring the expansion of non-traditional tradable sectors versus non-tradable industries, at least in the early stages of economic development (Gala 2008; Rodrik 2008a, 2009; Cimoli, Fleitas, and Porcile 2013).

Following Rodrik (2007), manufacturing development positively responds to a relatively depreciated and stable (real) exchange rate. On the contrary, exchange rate volatility can seriously hinder the emergence of new non-traditional tradable industries. In equation (4), $\rho$ stands for a measure of exchange rate volatility, namely exchange rate variance. In our model, perverse feedbacks between initial FDI flows, short-term portfolio investment, and exchange rate dynamics may give rise to exchange rate fluctuations, hence increasing $\rho$ values. On top of the initial appreciation phase in the exchange rate dynamics, such exchange rate volatility puts further strain on domestic manufacturing development.

In equation (4), we also think about a negative relationship between manufacturing development and net portfolio capital inflows. Such an assumption does not depend on any specific empirical evidence. Studies have mostly focused on the effects of portfolio capital flows on general macroeconomic dynamics and volatility rather than on possible effects on the sectorial composition of the recipient economy. Nonetheless, it seems reasonable to assume that other non-tradable sectors can benefit from a surge in portfolio foreign investment. This is, for example, the case of financial services or the real estate sector that can better exploit chances to get easy access to cheap external finance and use it to speculate on domestic financial assets (Taylor 1998). ${ }^{13}$

Finally, manufacturing GDP share is negatively affected by the size of the domestic natural resources sector, here represented by the capital stock $K_{N R}$ invested in the natural resources industry.

Equation (5) describes the essence of the Kaldorian argument on the pro-growth properties characterizing manufacturing. We assume a positive relationship between manufacturing GDP share $m$ and the overall labor productivity growth rate $y_{l}$.

\footnotetext{
${ }^{13}$ See IMF (2009) on the asymmetric response of service and manufacturing sectors to economic cycles. Service and real estate sectors have been relevant sources of employment creation during (perhaps) finance-led expansions since 1970. Manufacturing employment has traditionally been the main victim of contractions.
} 
$y_{l}=g(m)$

With $\left(\partial y_{l} / \partial m\right)>0$ and $\partial\left(\partial y_{l} / \partial m\right) / \partial m<0$

The long-run development effects of the medium-run dynamics described in the previous part of the paper pass through the relationships formalized in equations (4) and (5). These relationships are depicted in figure 3.

In the top-left panel of figure 3, we put in relation those values of the exchange rate $e$ and net portfolio capital flows $W A_{P I}$ that keep manufacturing GDP shares constant. According to the signs of the partial derivatives' to equation (4), the locus for constant $m$ values slopes upwards. In figure 3, the " $m_{A}$ curve" represents all possible $e-W A_{P I}$ combinations that keep the manufacturing GDP share equal to $m_{A}$, i.e., its initial value in the equilibrium point A. Points below (above) the " $m_{A}$ curve" stand for levels of manufacturing development lower (higher) than $m_{A}$. According to equation (4), the position of the map of contour curves for different $m$ values depends on $\rho$ and $\mathrm{K}_{\mathrm{N}}$. Should $\rho$ and/or $K_{N}$ increase, the isocline for values of $m$ equal to $m_{A}$ will move upwards. Given net portfolio flows, a depreciation of the exchange rate must materialize in order to prevent the manufacturing contribution to GDP from declining.

The top-right panel of figure 3 depicts the positive relationship between the exchange rate $e$ and $m$ as encapsulated in equation (4). Ultimately, the bottom-left panel of figure 3 reproduces the positive link between manufacturing development and the overall labor productivity growth.

Now let us assume that a natural resources boom attracts new FDIs. The capital stock $K_{N R}$ will increase and natural resources production (and exports) expand. Ceteris paribus, this will imply a direct contraction of the manufacturing GDP share. In the top-left panel of figure 3, this shock is represented by a parallel upward shift of the " $m_{A}$ isocline” (from $m_{A}$ to $m_{A}{ }^{l}$ ).

Apart from this first direct effect, initial FDI sets in motion the cyclical dynamics described in section 2. This fact is portrayed in the top-left panel of figure 3 by the black dotted line. The economy will move away from the initial equilibrium $A$ and fluctuate around the final equilibrium $B$. Along the cyclical traverse towards the new equilibrium, increasing exchange rate volatility will take place (at least with respect to the initial steady state), and $\rho$ will increase in equation (4). These exchange rate fluctuations can certainly jeopardize manufacturing development even further. In the top-left panel of figure 3, a perverse second-round upward shift in the " $m_{A}$ isocline" (from $m_{A}{ }^{1}$ to $m_{A}^{2}$ ) will eventually occur. 


\section{Figure 3. Long-run effects of a financial Dutch disease}

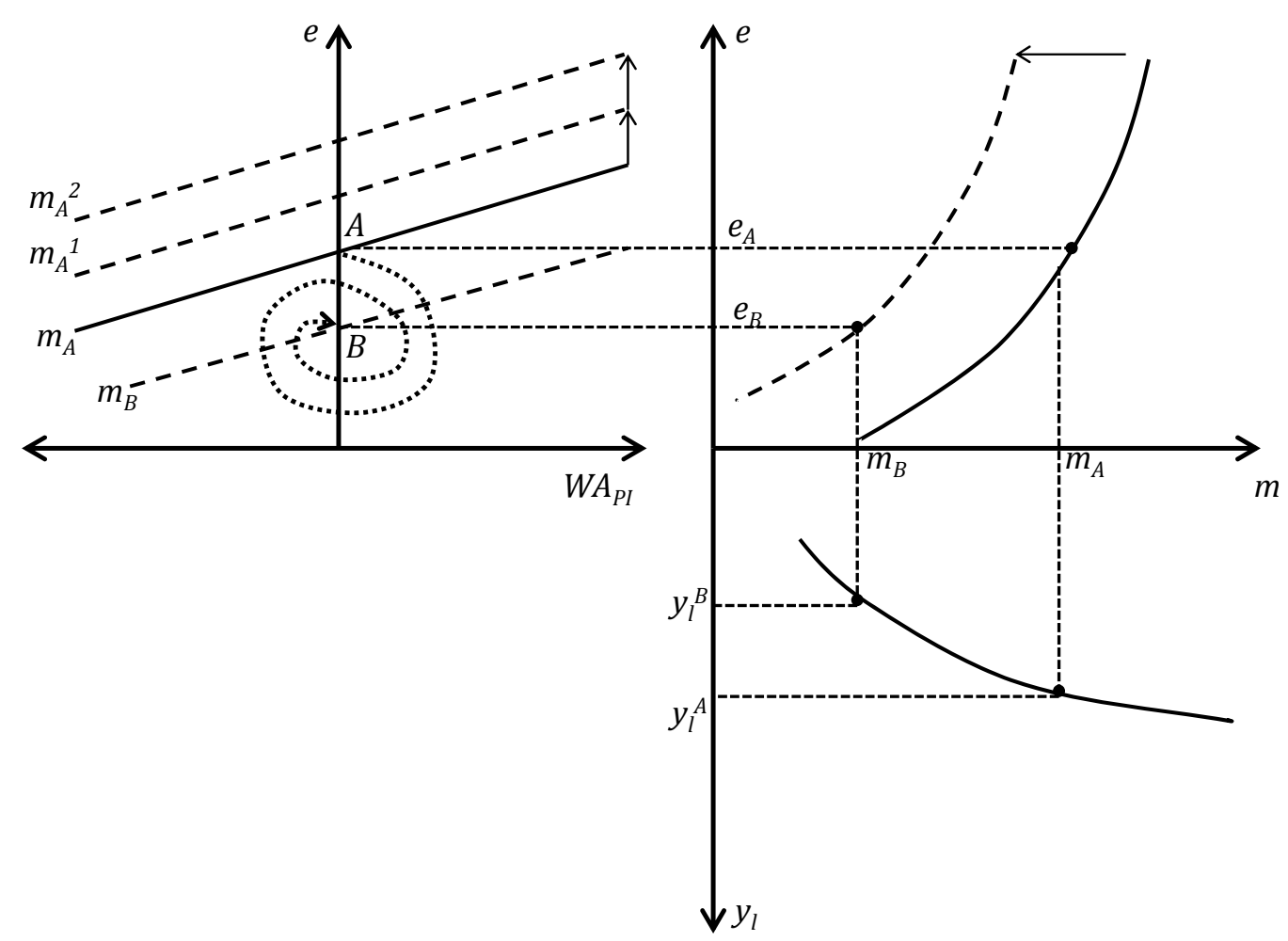

In point $\mathrm{B}$, net portfolio capital flows are in equilibrium and the foreign debt stock is stable. The exchange rate $e$ will be at a lower and more appreciated long-run value than the initial one. Indeed, increasing exports of primary commodities on international markets may lead to a longterm persistent appreciation of the domestic currency, thus crowding out manufacturing exports. Domestic manufacturing will shrink even further. This outcome is in line with the argument originally put forward by Singh (2003, 209), who argues that "FDI surges, as those for example of portfolio investment, can lead to equally undesirable consequences such as exchange rate appreciation and reduced competitiveness of a country's tradable sector”

In the top-right panel of figure 3 we reproduce the long-run contraction of domestic manufacturing in the $(e-m)$ space. The leftward movement of the $(e-m)$ curve represents the effects on manufacturing development due to both the initial FDI shock and the ensuing exchange rate and macroeconomic volatility. The downward movement along the new dashed line from $e_{A}$ to $e_{B}$ is the outcome of the long-run exchange rate appreciation. Manufacturing participation to GDP eventually drops from $m_{A}$ to $m_{B}$. 
Consistent with our assumptions, the upward sloping curve in the bottom-left panel of figure 3 shows the positive link between manufacturing development and overall labor productivity dynamics. It also shows the possible worrisome long-run effects of such a financial Dutch disease. FDIs in natural resource sectors, unstable portfolio capital flows, and a permanent exchange rate appreciation may eventually lead to a permanent slowdown in the growth rate of labor productivity and in the pace of economic development.

\section{POLICY OPTIONS}

The long-run negative effects on labor productivity dynamics due to such a financial Dutch disease are not automatic. First, these effects depend on how FDI integrates with the rest of the domestic productive system, which in turn depends, at least partially, on the industrial policy implemented by domestic authorities. Second, exchange rate volatility and financial turbulences might be tamed through specific measures adopted by monetary and fiscal institutions. In both cases, domestic authorities may be expected to intervene in order to neutralize the perverse medium- and long-run outcomes outlined above.

The kind of policies used in tackling the Dutch disease depends on the specific mechanisms through which the phenomenon develops. The OECD (2013), for instance, recognizes the existence of an ongoing deindustrialization process in Colombia and describes it using standard real-side Dutch disease models. In accordance, the OECD recommends a set of restrictive fiscal and monetary policies in order to tame possible perverse effects of the ongoing natural resource-FDI boom. The OECD first claims that in moments of economic bonanza restrictive fiscal policies may help to reduce inflationist pressures due to higher domestic expenditures, and create a fiscal buffer to deploy in the event of future drops in the price of primary commodities. Second, monetary policy should focus on price stability, perhaps increasing the target interest rate and (hence) indirectly reinforcing the appreciation of the nominal exchange rate to meet its own inflation target. Third, in presence of a permanently appreciated market-driven nominal exchange rate, the need to maintain a competitive real exchange rate should be pursed via structural measures. The emphasis here is on the lifting of restrictive minimum wage regulation and the support of infrastructure investment raising overall factor productivity.

This paper analyzes Dutch disease phenomena, including the Colombian one, under a different perspective, as it focuses on financial processes and how Dutch disease can develop through channels that are basically overlooked by the standard literature. Therefore, a different set of policies should be considered to tackle it. We focus on two specific topics that mainly concern 
macroeconomic policies rather than long-run industrial ones, even though relevant overlaps exist between the two types of measures (Rodrik 2008b). The first issue refers to financial flow controls; the second one refers to the exchange rate policy implemented by domestic monetary authorities, hence on the management of foreign reserves.

Exchange rate fluctuations and financial turbulences described originate from an initial surge in FDI that triggers a vicious spiral between volatile capital flows and exchange rate dynamics. The destabilizing effects of short- and medium-term capital flights are clear. This paper provides further support to the already existing idea that short- and medium-term foreign portfolio investment should be tightly controlled. In particular, it might be useful to sharply reduce the sensitiveness of capital flows to exchange rate changes. On top of possible quantitative restrictions, we would take into consideration taxation schemes that target capital gains emerging from the appreciation of exchange rate. Taxes on capital gains may first discourage speculation on the domestic equity market; second, they may curb domestic agents’ propensity to search for financial resources on international markets to deploy on speculative activities on domestic assets. This might significantly contribute the reduction of domestic agents’ exposure to foreign debt.

In order to clarify this point, let us assume that policy intervention is successful is removing destabilizing connections between portfolio foreign investment and the exchange rate. The locus for $(\dot{D}=0)$ gets vertical (see figure 4 , below). On top of this, the locus for ( $\dot{e}=0$ ) may turn out to be positively sloped. Once we have removed destabilizing forces connecting $e$ to $\dot{e}$ through boom-andbust dynamics in portfolio capital flows, a depreciation of the exchange rate will more easily improve the trade balance and the overall balance of payments, provided that the Marshall-LearnerRobinson condition holds true. In this new framework, FDI targeting domestic natural resources will still appreciate the exchange rate, hence undermining the competitiveness of domestic manufacturing; yet, exchange rate volatility and financial turmoil will be avoided and the system will become stable. This ì will positively affect long-run economic development and the relative expansion of manufacturing by providing a more stable and safer context for making long-run and often irreversible production and investment decisions. 


\section{Figure 4. Short-term capital flow controls and macroeconomic stabilization}

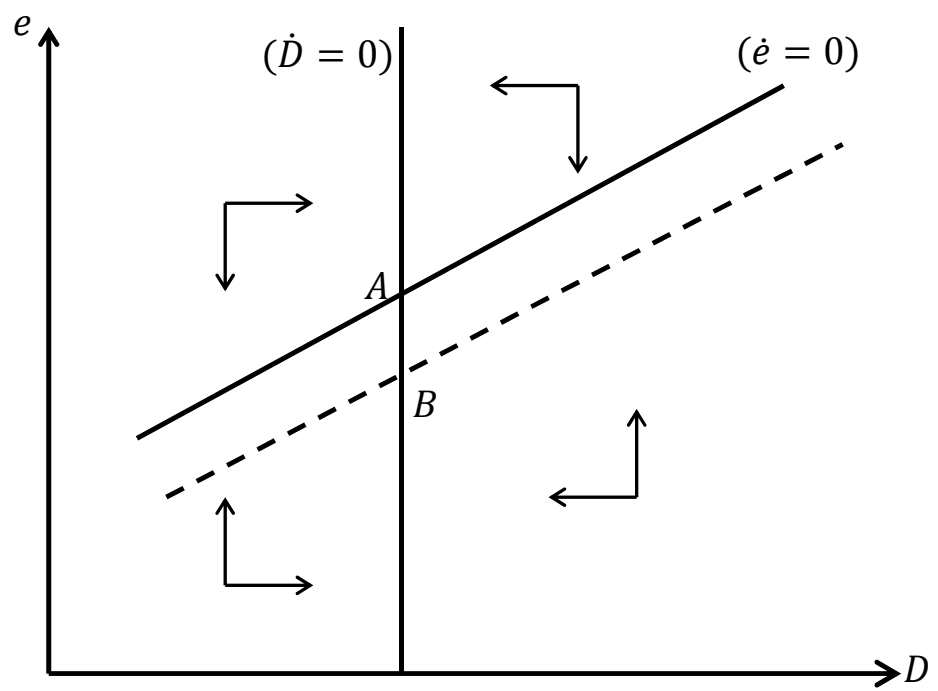

In spite of a much more stable macroeconomic environment, FDI-induced pressures on exchange rate appreciation will continue to jeopardize manufacturing development. In order to effectively face this problem, the domestic central bank could intervene on the currency market and avoid nominal appreciation by increasing its own foreign reserves. A rise in $\dot{R}$ will help to bring the isocline for $(\dot{e}=0)$ back to its original position or shift it upward in figure 4 . The domestic exchange rate could thus remain constant or even depreciate. Perverse effects of FDI on the competitiveness of domestic non-traditional tradable sectors will be neutralized or even reverted.

More generally, we consider an economic scenario in which a FDI-induced surplus in the home economy external account initially drives home currency to appreciate. According to Frenkel (2007, 2008), this is the context in which the well-known trilemma does not hold true. The domestic central bank can thus intervene on the currency market, accumulate foreign reserves, maintain an independent monetary policy, and control the exchange rate according to its own objectives, even in presence of unfettered capital movements. Domestic monetary authorities could be actively involved in fostering the home economy's long-run development process and recognize the importance that the exchange rate plays to favor sectorial and export diversification. They could aim at controlling the nominal exchange rate in order to keep the real exchange rate competitive and consistent with domestic industrialization. Such a monetary stance largely departs from a strict inflation-targeting monetary policy. Monetary policy should pursue a wider range of goals far beyond price stability. One the one hand, the attempt to keep inflation under control should be maintained and pursued through a tight coordination between monetary, fiscal, and social policies. 
On the other hand, monetary policy should take a much more developmental stand and support domestic production development by targeting an international competitive nominal and real exchange rate. Past experience has revealed that exchange rate pegs and external nominal anchors are very likely to give rise to speculative attacks and cannot protect developing countries from the risks posed to economic development by appreciating real exchange rates. Inflation-targeting monetary policy and market-driven exchange rate fluctuations, however, seem not to provide a reliable alternative, as exchange rate and macroeconomic volatility can be rather high and pressures on nominal and real exchange appreciation will persist. In other words, the best BoPs/exchange rate regime seems to be a managed, and sometimes strictly managed, exchange rate regime in which domestic monetary authorities target a competitive (and stable) real exchange rate in order to favor growth and employment (Ocampo 2013). There is increasing evidence that this kind of policy has proven effective for a number of East Asian countries (Sachs 1985; Gala 2008; Cimoli, Fleitas, and Porcile 2013). The undesirable long-run effects of FDI-driven Dutch disease must be faced and a larger consensus has been reached over that (Ros 2011; Bresser-Pereira 2012). This paper contributes to provide theoretical support to such positions. 


\section{REFERENCES}

Botta, A., A. Godin, and M. Missaglia. 2014. "Finance, Foreign (Direct) Investment, and the Dutch disease: The case of Colombia.” University of Pavia DEM Working Paper n. 90.

Bresser-Pereira, C. 2012. "Structuralist macroeconomics and the new developmentalism.” Brazilian Journal of Political Economy 32(3): 347-66.

Bruno, M., and J.D. Sachs. 1982. "Energy and Resource Allocation: A Dynamic Model of the 'Dutch Disease.”” Review of Economic Studies 49(5): 845-59.

Cimoli, M., M. Fleitas, and G. Porcile. 2013. "Technology Intensity of the Export Structure and the Real Exchange Rate.” Economics of New Technology and Innovation 22(4): 353-72.

Corden, W.M., and J.P. Neary. 1982. "Booming sector and de-industrialization in a small open economy.” The Economic Journal 92(368): 825-48.

Dutt, A.K. 1997. “The Pattern of Direct Foreign Investment and Economic Growth.” World Development 25(11): 1925-36.

Edwards, S. 2006. “The Relationship Between Exchange Rates and Inflation Targeting Revisited.” NBER Working Paper n. 12163.

Epstein, G., and A.E. Yeldan. 2009. "Beyond Inflation Targeting: Assessing the Impacts and Policy Alternatives.” in G. Epstein and A.E. Yeldan (eds.) Beyond Inflation Targeting. Cheltenham and Northampton, MA: Edward Elgar.

Frenkel, R. 2007. “The Sustainability of Monetary Sterilization Policy.” Cepal Review 93: 23-36.

Frenkel, R. 2008. “Competitive Real Exchange Rate Regime, Inflation, and Monetary Policy.” Cepal Review 96: 191-201.

Frenkel, R., and M. Rapetti. 2009. “A Developing Country View of the Current Global Crisis: What should not be forgotten and what should be done." Cambridge Journal of Economics 33(4): 685-702.

Gala, P. 2008. "Real Exchange Rate Levels and Economic Development: Theoretical Analysis and Econometric Evidence.” Cambridge Journal of Economics 32(2): 273-88.

Galindo, L.M., and J. Ros. 2006. “Alternatives to Inflation Targeting in Mexico.” PERI Working Paper 2006/7.

Gallagher, K.P., S. Griffith-Jones, and J.A. Ocampo. 2012. “Capital Account Regulation for Stability and Development: A New Approach.” in Regulating Global Capital Flows for Long-run Development, Pardee Center Task Force, March.

Gemayel, E.R., S. Jahan, and A. Peter. 2011. "What Can Low-Income Countries Expect from Adopting Inflation Targeting?” IMF Working Paper n. 276. 
Goda, T., and A. Torres. 2013. "Overvaluation of the Real Exchange Rate and the Dutch Disease: The Colombian Case.” CIEF Working Paper n. 28-13.

Klinger, B., and D. Lederman. 2004. "Discovery and Development: An Empirical Exploration of New Products.” World Bank Policy Research Paper n. 3450.

Krugman, P. 1999. “The Return of Depression Economics.” Foreign Affairs 98(1).

Imbs, J., and R. Warzciag. 2003. "Stages of Diversification.” American Economic Review 93(1): 63-86.

IMF. 2009. World Economic Outlook (October 2009): Sustaining the Recovery. Washington, DC: IMF Publishing.

Lall, S. 2000. “FDI and Development: Policy and Research Issues in the Emerging Context.” QEH Working Paper Series n. 43.

Lavopa, A., and A. Szirmai. 2012. “Industrialization, employment and poverty.” MERIT Working Paper n. 081.

Mansoorian, A. 1991. "Resource Discoveries and Excessive External Borrowing.” The Economic Journal 101(409): 1497-1509.

Manzano, O., and R. Rigobon. 2001. "Resource Curse or Debt Overhang.” NBER Working Paper n. 8390.

Masson, P.R., M.A. Savastano, and S. Sharma. 1997. "The Scope for Inflation Targeting in Developing Countries.” IMF Working Paper n. 130.

McMillan, M., and D. Rodrik. 2011. "Globalization, Structural Change and Productivity Growth.” NBER Working Paper n. 17143.

Mishkin, F.S. 1999. "Lessons from the Asian Crisis.” Journal of International Money and Finance 18(4): 709-23.

Mishkin, F.S. 2000. “Inflation Targeting in Emerging Market Countries.” NBER Working Paper n. 7618.

Mohanty, M.S., and M. Klau. 2005. "Monetary Policy Rules in Emerging Market Economies: Issues and Evidence.” in R.J. Langhammer and L. Vinhas de Souza (eds.) Monetary Policy and Macroeconomic Stabilization in Latin America. Berlin: Springer.

Neftci, S.N. 1998. "FX Short Positions, Balance Sheets and Financial Turbulence: An Interpretation of the Asian Financial Crisis.” CEPA Working Paper n. 11.

Ocampo, J.A. 2013. “Balance of Payments Dominance: Its Implications for Macroeconomic Policy. IPD Working Paper, October. Available at:

http://policydialogue.org/files/publications/Balance_of_payments_dominance_Ocampo.pdf.

OECD. 2013. OECD Economic Assessment of Colombia 2013. Available at: www.oecd.org/Colombia. 
Ojeda, J.N., A. Parra-Polonia, and C.O. Vargas. 2014. "Natural-Resource Booms, Fiscal Rules and Welfare in a Small Open Economy.” Banco de la Republica Colombiana Borradores de Economia n. 807.

Pontines, V., and R.Y. Siregar. 2012. "Exchange Rate Asymmetry and Flexible Exchange Rates under Inflation Targeting Regimes: Evidence from four East and Southeast Asian Countries.” Review of International Economics 20(5): 893-908.

Rajan, R.G., and A. Subramanian. 2011. “Aid, Dutch Disease and Manufacturing Growth.” Journal of Development Economics 94(1): 106-18.

Rodrik, D. 2007. “Industrial Development: Some Stylised Facts and Policy Directions.” in UNDESA (ed.) Industrial Development for the 21st Century: Sustainable Development Perspectives. New York: UN Publishing.

Rodrik, D. 2008a. “The Real Exchange Rate and Economic Growth.” Brookings Papers on Economic Activity 39(2): 365-439.

Rodrik, D. 2008b. “Normalizing Industrial Policy.” Commission on Growth and Development Working Paper n. 3. Washington, DC: World Bank.

Rodrik, D. 2009. “Growth After the Crisis.” CEPR Discussion Paper n. 7480.

Ros, J. 2001. "Industrial Policy, Comparative Advantages and Growth.” CEPAL Review 73: 12745.

Ros, J. 2011. “How to Neutralize the Adverse Developmental Effects of the Dutch Disease.” Paper presented at the International Workshop "New Developmentalism and a Structuralist Development Macroeconomics,” August 15-16, Sao Paulo, Brazil. Available at: http://cemacro.fgv.br/en/node/447.

Sachs, J.D. 1985. "External Debt and Macroeconomic Performance in Latin America and East Asia.” Brookings Papers on Economic Activity 2: 523-73.

Sachs, J.D., and A.M. Warner. 1995. “Natural Resource Abundance and Economic Growth.” NBER Working Paper n. 5398.

Sachs, J.D., and A.M. Warner. 2001. "The curse of natural resources.” European Economic Review 45(4): 827-38.

Singh, A. 2003. “Capital Account Liberalization, Free Long-term Capital Flows, Financial Crises and Economic Development.” Eastern Economic Journal 29(2): 191-216.

Stiglitz, J. 2002. Globalization and its Discontents. New York and London: W.W. Norton and Company.

Taylor, L. 1998. “Capital Market Crises: Liberalization, Fixed Exchange Rates and Market-driven Destabilization.” Cambridge Journal of Economics 22(6): 663-76.

Taylor, L. 2004a. Reconstructing Macroeconomics. Cambridge, MA and London: Harvard University Press. 
Taylor, L. 2004b. "Exchange Rate Indeterminacy in Portfolio Balance, Mundell-Fleming and Uncovered Interest Parity Models.” Cambridge Journal of Economics 28(2): 205-27. 